Article

\title{
Enhanced Expression of IGFBP-3 Reduces Radiosensitivity and Is Associated with Poor Prognosis in Oral Squamous Cell Carcinoma
}

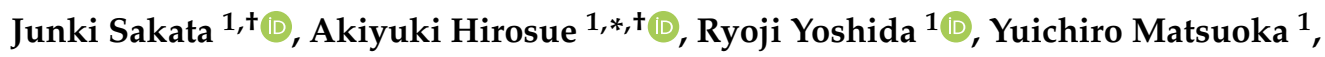 \\ Kenta Kawahara ${ }^{1}$, Hidetaka Arita ${ }^{1}$, Hikaru Nakashima ${ }^{1}$, Tatsuro Yamamoto ${ }^{1}$, Masashi Nagata ${ }^{1}$, \\ Sho Kawaguchi ${ }^{1}$, Shunsuke Gohara ${ }^{1}$, Yuka Nagao ${ }^{1}$, Keisuke Yamana ${ }^{1}$, Ryo Toya ${ }^{2}$ (D), \\ Ryuji Murakami ${ }^{3}$, Yoshikazu Kuwahara ${ }^{4}$, Manabu Fukumoto ${ }^{5}$ and Hideki Nakayama ${ }^{1, *}$ (1) \\ 1 Department of Oral and Maxillofacial Surgery, Faculty of Life Sciences, Kumamoto University, \\ Kumamoto 860-8556, Japan; jsakata@kuh.kumamoto-u.ac.jp (J.S.); ryoshida@kumamoto-u.ac.jp (R.Y.); \\ yu6600@kuh.kumamoto-u.ac.jp (Y.M.); karapote@kuh.kumamoto-u.ac.jp (K.K.); \\ haritah1@aih-net.com (H.A.); hikarun@kuh.kumamoto-u.ac.jp (H.N.); tatsuro.yamamoto@jfcr.or.jp (T.Y.); \\ nagatama0213@kuh.kumamoto-u.ac.jp (M.N.); idd09017m@kuh.kumamoto-u.ac.jp (S.K.); \\ shun2707@kuh.kumamoto-u.ac.jp (S.G.); dd09034w@kuh.kumamoto-u.ac.jp (Y.N.); \\ idd09053y@kuh.kumamoto-u.ac.jp (K.Y.) \\ 2 Department of Radiation Oncology, Kumamoto University Hospital, Kumamoto 860-8556, Japan; \\ ryo108@kumamoto-u.ac.jp \\ 3 Department of Medical Imaging, Faculty of Life Sciences, Kumamoto University, Kumamoto 862-0976, Japan; \\ murakami@kumamoto-u.ac.jp \\ 4 Radiation Biology and Medicine, Faculty of Medicine, Tohoku Medical and Pharmaceutical University, 4-4-1, \\ Komatsushima, Aoba, Sendai, Miyagi 981-8558, Japan; y-kuwahara@umin.ac.jp \\ 5 Department of Molecular Pathology, Tokyo Medical University, 6-1-1, Shinjuku, Shinjuku, Tokyo 160-8402, \\ Japan; manabu.fukumoto.a8@tohoku.ac.jp \\ * Correspondence: ahiro711@kumamoto-u.ac.jp (A.H.); hinakaya@kumamoto-u.ac.jp (H.N.); \\ Tel.: +81-96-373-5288 (A.H. \& H.N.) \\ + These authors contributed equally to this work.
}

Received: 15 January 2020; Accepted: 18 February 2020; Published: 20 February 2020

\begin{abstract}
Insulin-like growth factor (IGF) binding protein-3 (IGFBP-3) modulates various cell functions through IGF-dependent or independent mechanisms. However, its biological roles in the radiosensitivity of oral squamous cell carcinoma (OSCC) remain largely unknown. The purpose of this study was to determine the clinical significance and molecular mechanisms of the association between IGFBP-3 and OSCC radiosensitivity. We performed an immunohistochemical analysis of IGFBP-3 in 52 OSCC specimens from patients treated with preoperative chemoradiotherapy and surgery (phase II study). Associations between IGFBP-3 expression and clinicopathological features were also evaluated. In addition, we examined the effects of IGFBP-3 on post-X-ray irradiation radiosensitivity and DNA damage in vitro. High IGFBP-3 expression was significantly correlated with poor chemoradiotherapy responses and prognosis. With IGFBP-3 knockdown, irradiated OSCC cells exhibited significantly higher radiosensitivity compared with that of control cells. Moreover, IGFBP-3 depletion in OSCC cells reduced phosphorylation of the DNA-dependent protein kinase catalytic subunit (DNA-PKcs), which is required for DNA double-strand break repair during non-homologous end joining. These findings indicate that IGFBP-3 may have a significant role in regulating DNA repair and is be a potential biomarker for predicting clinical response to radiotherapy and prognosis in OSCC.
\end{abstract}

Keywords: DNA repair; IGFBP-3; oral squamous cell carcinoma; DNA-PKcs; radiosensitivity 


\section{Introduction}

Oral cancer, and especially oral squamous cell carcinoma (OSCC), is among the most common cancers worldwide [1]. Despite innovation and advances in diagnostic techniques and treatment, the prognosis for this disease has not improved [2]. As such, potential malignancy leading to therapeutic resistance has yielded unsatisfactory results.

Radiotherapy, currently a predominant component of OSCC treatment, effectively kills cancer cells by inducing DNA damage [3]. However, OSCC cells frequently develop radioresistance by activating the DNA-damage response, controlling the generation of reactive oxygen species, and modulating immune responses [4]. Although radioresistance is a major clinical obstacle for OSCC, the detailed underlying molecular mechanisms are still unknown.

Insulin-like growth factor binding protein-3 (IGFBP-3) is one of six secreted IGFBP-family proteins that regulate insulin-like growth factor (IGF) signalling [5]; however, IGFBP-3 also has IGF-independent functions, including cellular uptake and nuclear import [6]. Moreover, many studies have examined the relationship between circulating IGFBP-3 and carcinogenesis risk or prognosis, but only a few consistent associations have been reported [7]. For example, circulating IGFBP-3 was not found associated with pancreatic, colorectal, ovarian, or breast cancer risk [8-12]. In lung cancer, however, circulating IGFBP-3 has an inverse correlation with cancer risk [13], while IGFBP-3 plasma levels in prostate cancer are associated with cancer incidence and survival $[14,15]$. Meanwhile, other studies have indicated that tumour protein and mRNA levels of IGFBP-3 may be useful prognostic markers [7]. In breast cancer and glioblastoma, high expression levels of IGFBP-3 in cancer tissues are associated with decreased survival rates $[16,17]$. However, there have been no reports on the association between IGFBP-3 expression and prognosis in OSCC. The role of IGFBP-3 in therapeutic resistance is also unclear. Here, we investigated IGFBP-3 expression status in biopsy specimens obtained from patients with OSCC via an immunohistochemical analysis and determined that elevated IGFBP-3 expression is significantly correlated with poor response to preoperative chemoradiotherapy and a low survival rate. Furthermore, we demonstrated that IGFBP-3 confers radioresistance by activating DNA repair after X-ray irradiation in OSCC cells.

\section{Results}

\subsection{Clinical Significance of IGFBP-3 Expression in Patients with OSCC}

To determine the role of IGFBP-3 in OSCC, we collected biopsy specimens from 52 patients with OSCC to assess IGFBP-3 expression via immunohistochemistry. IGFBP-3 immunoreactivity was observed mainly in the nucleus and weakly in the cytoplasm of epithelial cells (Figure 1A,B). Patients were classified into low or high IGFBP-3 expression groups based on the immunostaining score for IGFBP-3. The results indicate a variety of immunostaining patterns in clinical OSCC samples, reflecting the biological properties of cancer cells. To illuminate the clinical implications of IGFBP-3 expression in OSCC, we examined correlations between IGFBP-3 expression and clinicopathological variables (Table 1). Of the 52 OSCC cases, 27 (51.9\%) showed high IGFBP-3 expression and 25 (48.1\%) showed low IGFBP-3 expression. As shown in Table 1, the frequency of tumours with high IGFBP-3 expression was significantly higher in patients associated with poor responses to preoperative chemoradiotherapy than in patients with good responses $(p=0.028)$. In contrast, no significant differences in IGFBP-3 expression were observed according to age, sex, primary site, clinical stage, T-stage, $\mathrm{N}$-stage, or differentiation. Moreover, to examine the effect of circulating IGFBP-3, we assessed expression levels in plasma obtained from 30 patients with OSCC. Plasma IGFBP-3 levels were not associated with tissue levels (Supplementary Figure S1) and there were no significant differences in terms of clinical features and prognosis (Supplementary Tables S1 and S2). 


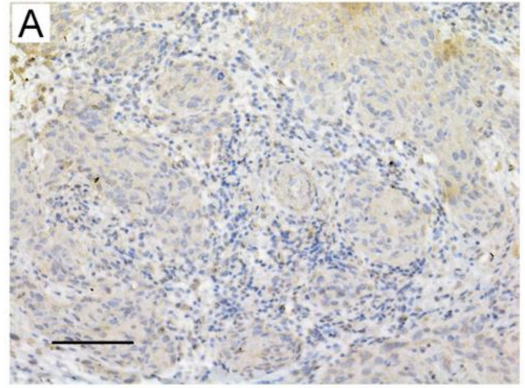

IGFBP-3-low

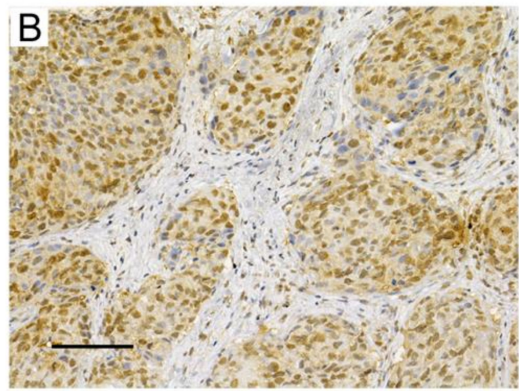

IGFBP-3-high

C

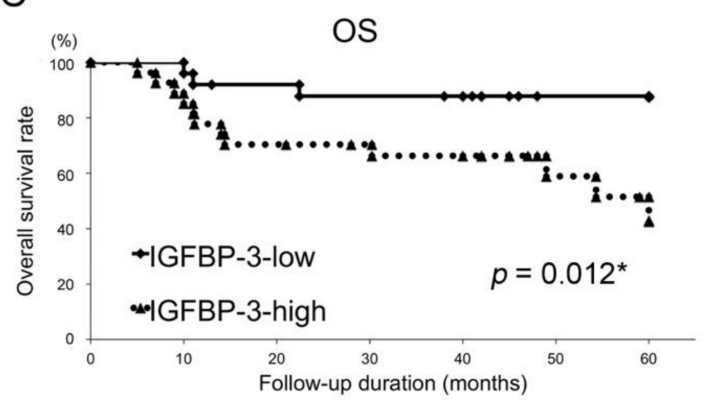

D

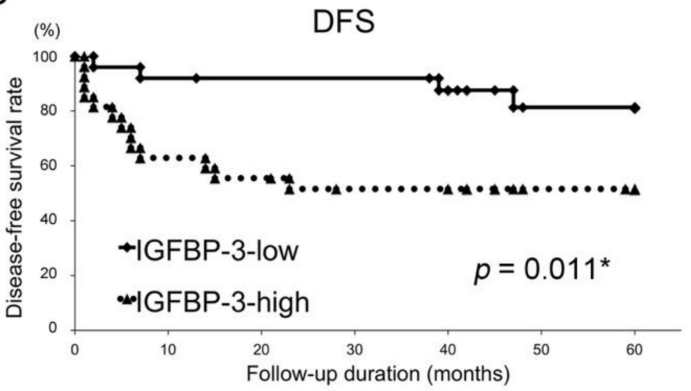

Figure 1. Tumour IGFBP-3 expression status affects the survival of patients with oral squamous cell carcinoma (OSCC). (A,B) Immunohistochemical staining for IGFBP-3 in OSCC biopsy specimens. Representative microscopic images show the characteristic expression status (A low expression; B high expression). Scale bar, $100 \mu \mathrm{m}$. (C,D) Overall survival (OS) (C) and disease-free survival (DFS) (D) of patients with OSCC based on IGFBP-3 expression status. ${ }^{*} p<0.05$.

Table 1. Correlation between IGFBP-3 expression and clinicopathological factors in 52 patients with oral squamous cell carcinoma (OSCC).

\begin{tabular}{|c|c|c|c|c|}
\hline \multirow{3}{*}{ Characteristic } & \multirow{3}{*}{ Total } & \multicolumn{2}{|c|}{ IGFBP-3 Status } & \multirow{3}{*}{$p$-Value } \\
\hline & & High Expression & Low Expression & \\
\hline & & $n(\%)$ & $n(\%)$ & \\
\hline & 52 & 27 (51.9) & $25(48.1)$ & \\
\hline \multicolumn{5}{|l|}{ Age, years } \\
\hline Median & 66.5 & 67.3 & 65.6 & \multirow{4}{*}{0.100} \\
\hline Range & $30-85$ & $30-85$ & $47-84$ & \\
\hline$\leq 65$ & 23 & $9(39.1)$ & $14(60.9)$ & \\
\hline$>65$ & 29 & $18(62.1)$ & $11(37.9)$ & \\
\hline \multicolumn{5}{|l|}{ Sex } \\
\hline Male & 31 & 13 (41.9) & 18 (58.1) & \multirow[t]{2}{*}{0.080} \\
\hline Female & 21 & 14 (66.7) & $7(33.3)$ & \\
\hline
\end{tabular}


Table 1. Cont.

\begin{tabular}{|c|c|c|c|c|}
\hline \multirow{3}{*}{ Characteristic } & \multirow{3}{*}{ Total } & \multicolumn{2}{|c|}{ IGFBP-3 Status } & \multirow{3}{*}{$p$-Value } \\
\hline & & High Expression & Low Expression & \\
\hline & & $n(\%)$ & $n(\%)$ & \\
\hline \multicolumn{5}{|l|}{ Primary site } \\
\hline Tongue & 16 & $9(56.3)$ & $7(43.7)$ & 0.570 \\
\hline Mandible gingiva & 15 & $8(53.3)$ & $7(46.7)$ & \\
\hline Maxilla gingiva & 7 & $5(71.4)$ & $2(28.6)$ & \\
\hline Buccal mucosa & 10 & $4(40.0)$ & $6(60.0)$ & \\
\hline Oral floor & 4 & $1(25.0)$ & $3(75.0)$ & \\
\hline \multicolumn{5}{|l|}{ Clinical stage } \\
\hline III & 18 & $10(55.6)$ & $8(44.4)$ & \\
\hline IV & 34 & $17(50.0)$ & $17(50.0)$ & \\
\hline \multicolumn{5}{|l|}{ pT-stage } \\
\hline T2 & 10 & $4(40.4)$ & $6(60.0)$ & 0.545 \\
\hline T3 & 24 & $12(50.0)$ & $12(50.0)$ & \\
\hline $\mathrm{T} 4$ & 18 & $11(61.1)$ & $7(38.9)$ & \\
\hline \multicolumn{5}{|l|}{ pN-stage } \\
\hline No & 31 & $18(58.1)$ & $13(41.9)$ & 0.282 \\
\hline$\geq \mathrm{N} 1$ & 21 & $9(42.9)$ & $12(57.1)$ & \\
\hline \multicolumn{5}{|l|}{ Differentiation } \\
\hline Well & 40 & $21(55.3)$ & 19 (44.7) & 0.879 \\
\hline Moderate, poor & 12 & $6(50.0)$ & $6(50.0)$ & \\
\hline \multicolumn{5}{|l|}{ Pathological response } \\
\hline Grade 0, I, II & 29 & 19 (65.5) & $10(34.5)$ & 0.028 * \\
\hline Grade III, IV & 23 & $8(34.8)$ & 15 (65.2) & \\
\hline
\end{tabular}

A chi-square test was used to examine the correlation between IGFBP3 expression and clinicopathological factors in 52 patients with OSCC. ${ }^{*} p<0.05$.

\subsection{Relationships between IGFBP-3 Expression and Survival}

To assess the relationships between IGFBP-3 expression and survival, 52 patients were analysed for overall survival (OS) and disease-free survival (DFS) using the Kaplan-Meier method. OS and DFS within the high IGFBP-3 expression group were significantly lower than in cases with low IGFBP-3 expression $(p=0.012$ and $p=0.011$, respectively; Figure $1 C, D)$. A multivariate analysis with the Cox proportional hazards regression model indicated that IGFBP-3 expression, $\mathrm{pN}$-stage, and pathological response to chemoradiotherapy are significant OSCC prognostic factors for patients (Table 2).

Table 2. Multivariate analysis of prognostic factors in patients with OSCC based on the Cox proportional hazards regression model and IGFBP-3 expression.

\begin{tabular}{|c|c|c|c|c|c|}
\hline \multirow{2}{*}{ Characteristic } & \multirow{2}{*}{ Assigned Score } & \multicolumn{2}{|l|}{ OS } & \multicolumn{2}{|l|}{ DFS } \\
\hline & & Hazard Ratio (95\% CI) & $p$-Value & Hazard Ratio (95\% CI) & $p$-Value \\
\hline \multicolumn{6}{|c|}{ IGFBP-3 expression } \\
\hline Low & 0 & $3.783(1.148-17.11)$ & $0.028 *$ & 3.878 (1.294-14.35) & 0.014 * \\
\hline High & 1 & & & & \\
\hline \multicolumn{6}{|l|}{ pN-stage } \\
\hline N0 & 0 & $2.951(1.033-8.598)$ & $0.043 *$ & $3.107(1.136-8.641)$ & $0.028 *$ \\
\hline$\geq \mathrm{N} 1$ & 1 & & & & \\
\hline \multicolumn{6}{|c|}{ Pathological response } \\
\hline Grade 0, I, II & 0 & $0.087(0.005-0.446)$ & $0.001 * *$ & $0.135(0.021-0.495)$ & $0.001 * *$ \\
\hline Grade III, IV & 1 & & & & \\
\hline
\end{tabular}

CI, confidence interval; DFS, disease-free survival; OS, overall survival. ${ }^{*} p<0.05,{ }^{* *} p<0.01$. 


\subsection{Effect of IGFBP-3 on Radiosensitivity in OSCC Cells}

To address the biological importance of IGFBP-3 in radiosensitivity, we employed clinically relevant radioresistant (CRR) OSCC cells [18]. Modified high-density survival (HDS) assays suggested that CRR cell line survival (both SAS-R and HSC2-R) was significantly enhanced compared with that of the corresponding parental cells under all exposure doses (Supplementary Figure S2). To examine IGFBP-3 expression levels in CRR cells, we performed quantitative reverse transcription PCR (qRT-PCR) and western blot analyses. The results show that IGFBP-3 expression is significantly increased at both the mRNA and protein level in SAS-R and HSC2-R cells compared with parental cells (Figure 2A,B). To further test whether IGFBP-3 affects radiosensitivity in irradiated OSCC cells, we performed modified HDS and clonogenic assays using small interfering RNA (siRNA)-mediated IGFBP-3 knockdown. Western blot and qRT-PCR analyses confirmed that IGFBP-3 was depleted at both the mRNA and protein levels (Figure 2C,D). For the modified HDS assay, each cell line was irradiated at 0, 2, 6, and 10 Gy. Irradiated CRR cells and parental cells with IGFBP-3 knockdown exhibited significantly increased radiosensitivity than that of control cells (Figure 2E,F); clonogenic assays also yielded similar results (Figure 2G,H). We then examined OSCC cellular growth activities after IGFBP-3 knockdown via cell proliferation assays and found that IGFBP-3 significantly affects cell proliferation (Supplementary Figure S3). Regarding the influence of cellular growth activity, the differences in proliferation were normalized to that of control cells in the modified HDS and clonogenic assays. Furthermore, IGFBP-3 knockdown did not affect OSCC cell sensitivity to cisplatin and 5-fluorouracil (Supplementary Figure S4). Collectively, our results suggest that IGFBP-3 confers resistance to radiation in OSCC cells.
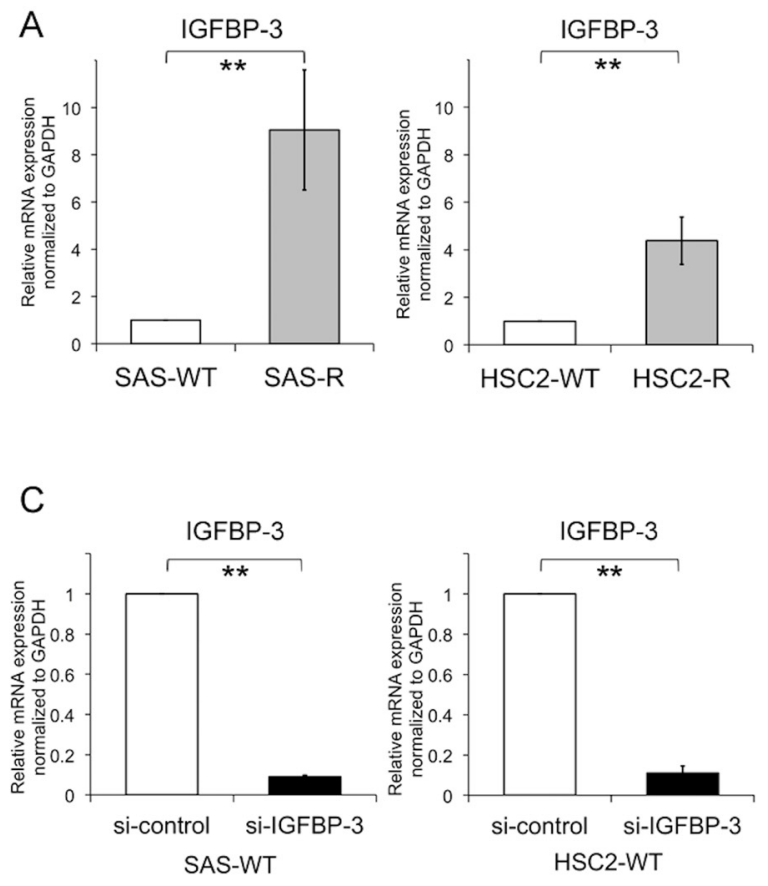

Figure 2. Cont.
B

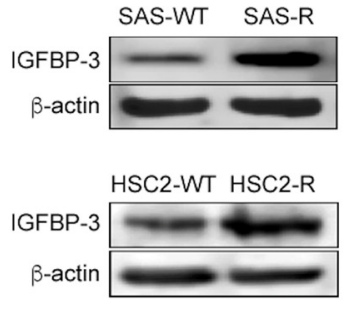

D

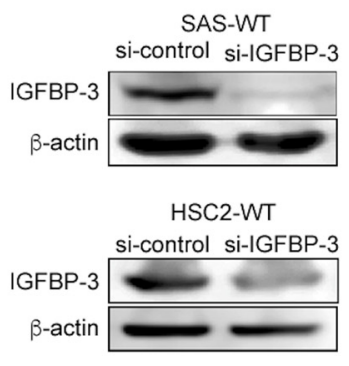


E

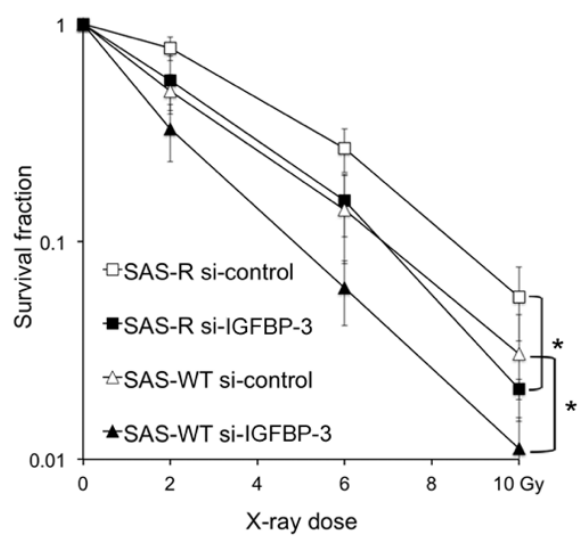

G

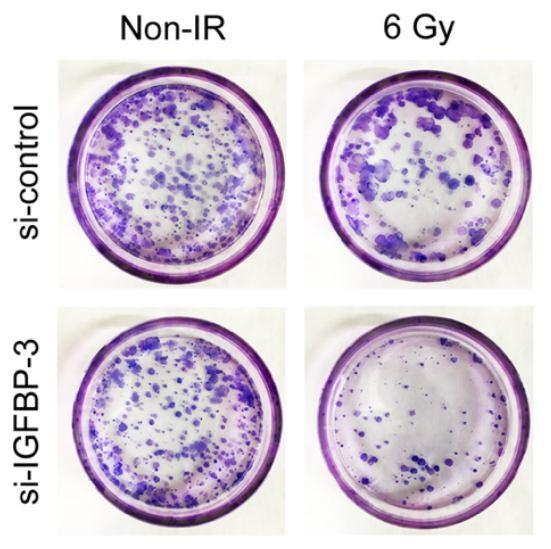

$\mathrm{H}$

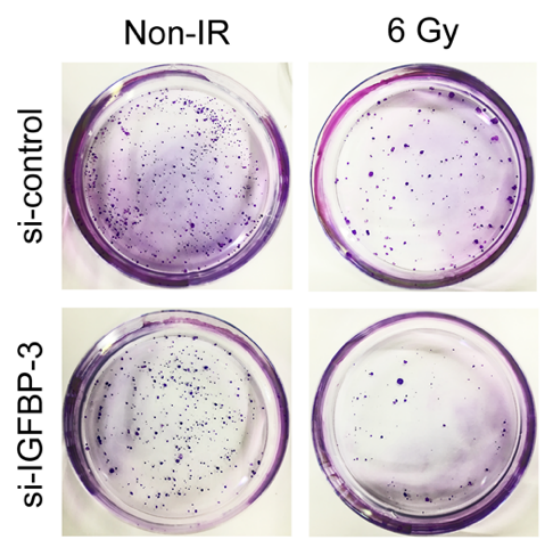

F
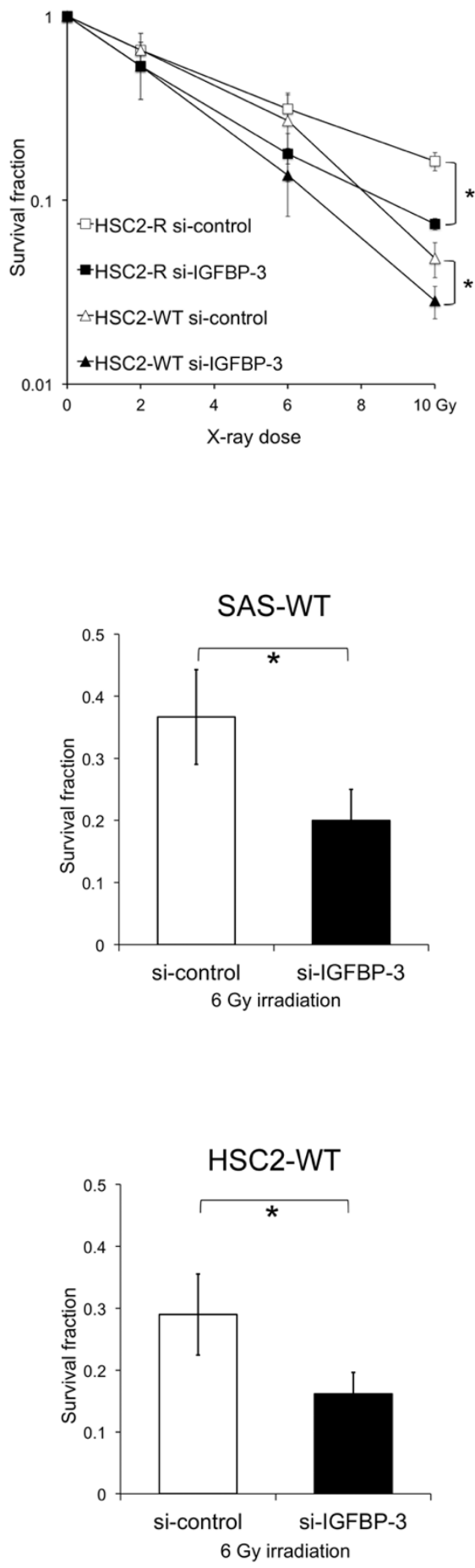

Figure 2. IGFBP-3 confers resistance to radiation in OSCC cells. (A,B) IGFBP-3 mRNA and protein expression levels in clinically relevant radioresistant (CRR) cells and parental cells. (C,D) IGFBP-3 mRNA and protein levels in SAS and HSC-2 cells after transfection with IGFBP-3 or control siRNA. Total RNA and whole-cell lysates were used for qRT-PCR $(\mathbf{A}, \mathbf{C})$ and Western blot analysis (B,D), respectively. (E,F) CRR and parental cells were transfected with IGFBP-3 or control siRNA and exposed to an X-ray dose of $0,2,6$, and $10 \mathrm{~Gy}$; the surviving fraction was then evaluated using a modified high-density survival (HDS) assay. (G,H) SAS and HSC-2 cells transfected with IGFBP-3 siRNA or control were exposed to $6 \mathrm{~Gy}$, and then the surviving fraction was evaluated by clonogenic assays. The results are shown as the means \pm SD of three independent experiments. ${ }^{*} p<0.05$. ${ }^{* *} p<0.01$. 


\subsection{Contribution of IGFBP-3 to Decreases in DNA Damage in Irradiated OSCC Cells}

Radiation can damage DNA stands and induce single- and double-strand breaks (DSBs). DSBs are more difficult to repair and are therefore more toxic and fatal to cancer cells [19]. To assess whether IGFBP-3 affects the number of DSBs in irradiated OSCC cells, we used $\gamma-\mathrm{H} 2 \mathrm{AX}$ as a quantifiable marker after X-ray irradiation and identified cells with $\geq 10 \gamma-\mathrm{H} 2 \mathrm{AX}$ foci at 0.5 and $24 \mathrm{~h}$ after $10-\mathrm{Gy}$ irradiation [20,21]. The frequency of $\gamma$-H2AX-positive SAS cells with IGFBP-3 knockdown $(65.0 \pm 7.8 \%)$ was higher than that in control cells $(45.3 \% \pm 7.2 \%)$ at $24 \mathrm{~h}$ (Figure $3 \mathrm{~A}, \mathrm{~B})$. These results suggest that IGFBP-3 helps to reduce DNA damage in irradiated OSCC cells.
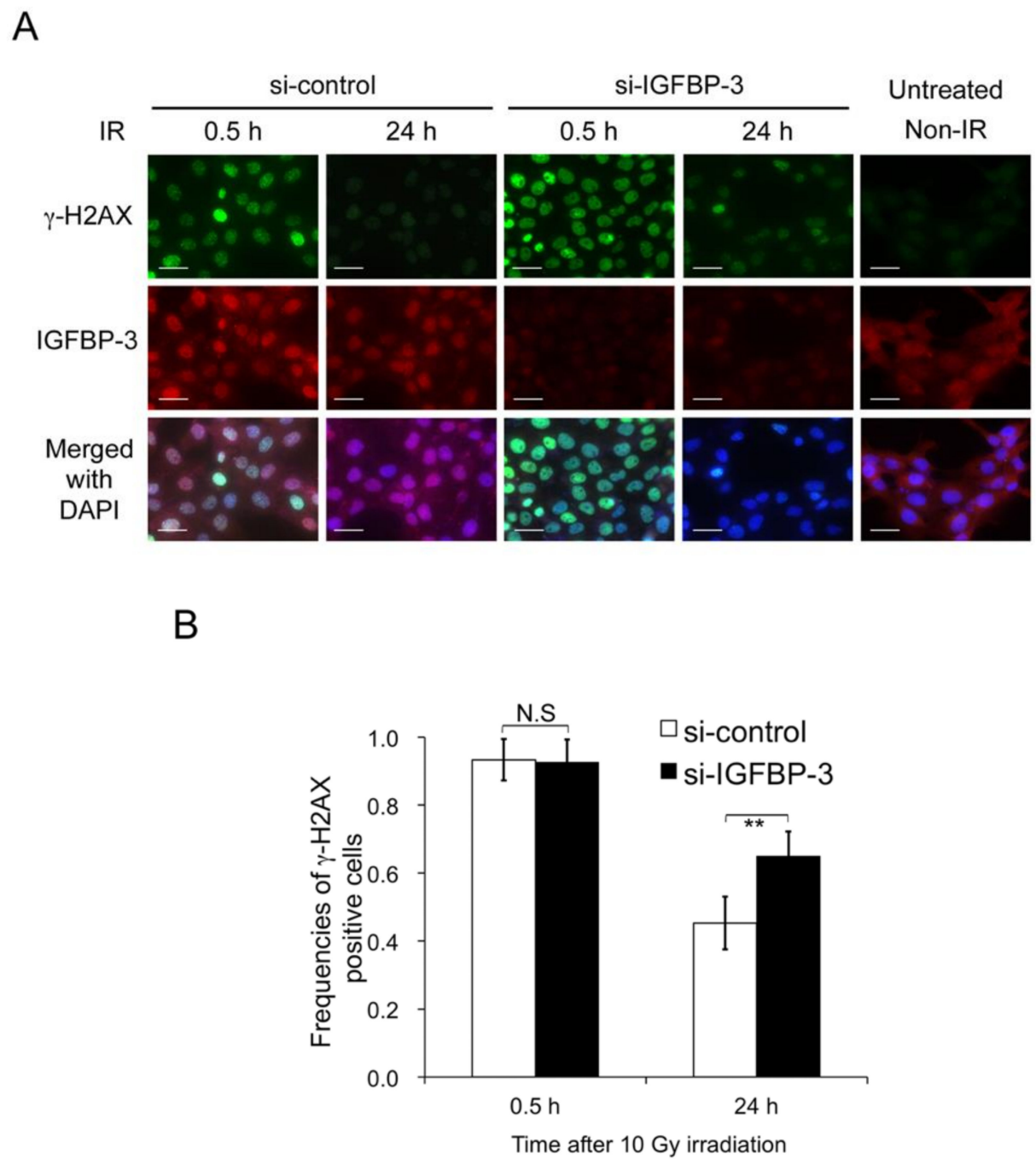

Figure 3. IGFBP-3 helps reduce DNA damage in irradiated OSCC cells. (A) Representative immunofluorescence images of $\gamma-\mathrm{H} 2 \mathrm{AX}$ foci and IGFBP-3 in SAS cells after exposure to 10 Gy irradiation (IR) following transfection with control or IGFBP-3-specific siRNA. (B) Frequencies of $\gamma$-H2AX-positive cells at each time point after irradiation and with or without IGFBP-3 inhibition. The results are shown as the means \pm SD of three independent experiments. ${ }^{* *} p<0.01$. Scale bar, $50 \mu \mathrm{m}$.

\subsection{Functional Role of IGFBP-3 in the DNA Repair of Irradiated OSCC Cells}

Radiation-induced DSBs can be repaired by two predominant processes: homologous recombination (HR) and non-homologous end joining (NHEJ) [22]. A previous study showed that NHEJ plays a dominant role, whereas HR has a supportive role [23]. In the NHEJ pathway, the DNA-dependent protein kinase catalytic subunit (DNA-PKcs) is essential for DSB repair [22], and the activity of this protein is associated with radioresistance [24]. Therefore, to further understand 
how IGFBP-3 is involved in DNA repair, we examined the activation of DNA-PKcs by assessing its phosphorylation at Ser2056 in IGFBP-3-knockdown OSCC cells after irradiation. While phosphorylated DNA-PKcs was not observed in non-irradiated cells, it was significantly enhanced in irradiated cells. IGFBP-3 knockdown markedly reduced this phosphorylation (Figure 4A), suggesting that IGFBP-3 plays an important role in DNA-PKcs activation.

A

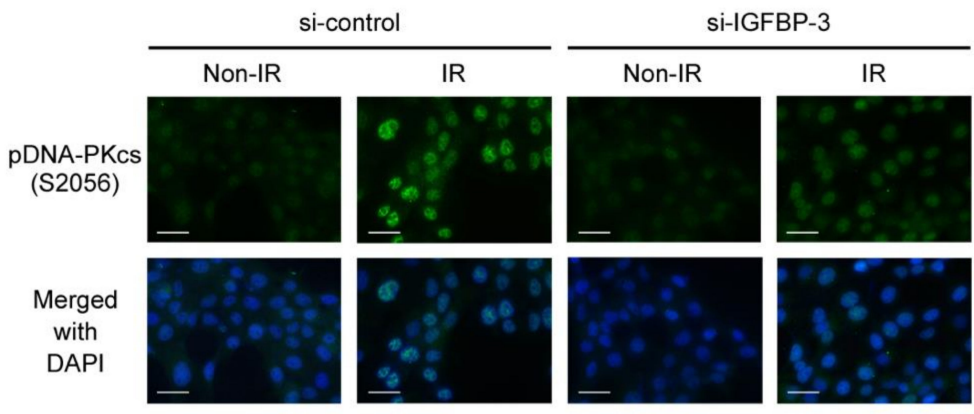

B

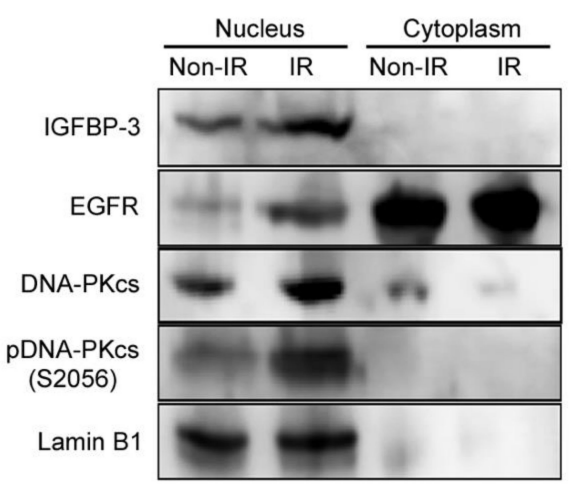

C
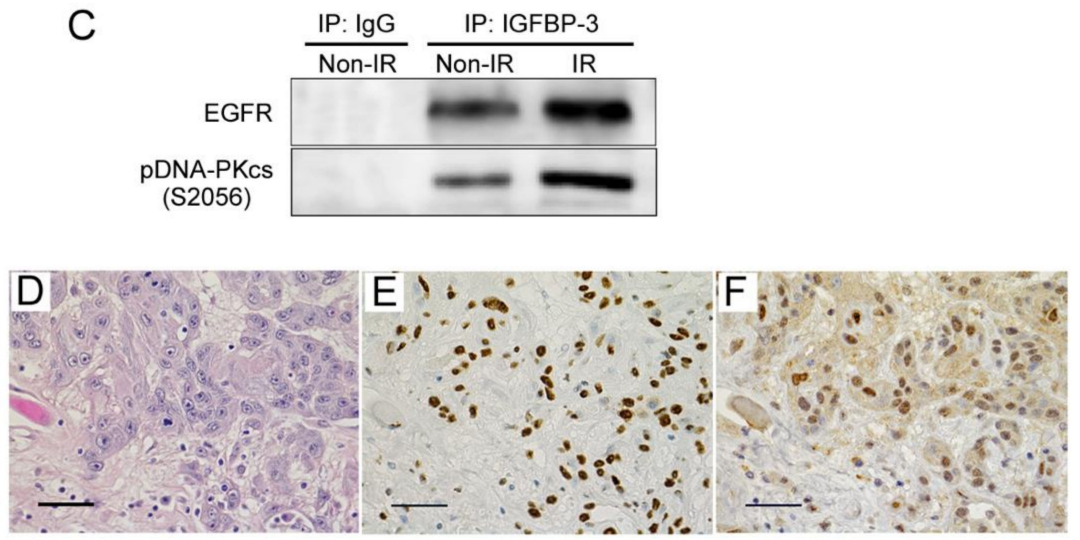

Figure 4. IGFBP-3 is involved in DNA-dependent protein kinase catalytic subunit (DNA-PKcs) activation by interacting directly with DNA-PKcs and epidermal growth factor receptor (EGFR) in irradiated OSCC cells. (A) Immunofluorescence for phospho-DNA-PKcs (S2056) in SAS cells $0.5 \mathrm{~h}$ after 0 or 10 Gy irradiation with or without IGFBP-3 knockdown. Scale bar, $50 \mu \mathrm{m}$. (B) Western blots of IGFBP-3, EGFR, DNA-PKcs, and phospho-DNA-PKcs protein levels in SAS cells at $0.5 \mathrm{~h}$ after 0 or 10 Gy irradiation. (C) IGFBP-3/EGFR and IGFBP-3/phospho-DNA-PKcs complex formation in SAS cells, as detected by immunoprecipitation (IP) assays. An anti-IGFBP-3 antibody was used to immunoprecipitate cell lysates, after which immunoprecipitates were subjected to immunoblotting with anti-EGFR and anti-phospho-DNA-PKcs antibodies. (D-F) Representative microscopic images of haematoxylin and eosin (D) and immunohistochemical staining for IGFBP-3 (E) and DNA-PKcs (F) in tumour tissues after chemoradiotherapy. Scale bar, $100 \mu \mathrm{m}$. 


\subsection{Interactions among IGFBP-3, EGFR, and Phosphorylated DNA-PKcs in Irradiated OSCC Cells}

A recent study revealed that nuclear translocation of epidermal growth factor receptor (EGFR) contributes to radioresistance by activating DNA-PKcs phosphorylation [25]. To assess the interactions among IGFBP-3, EGFR, and phosphorylated DNA-PKcs in irradiated OSCC cells, we performed a Western blot analysis and immunoprecipitation. After $0.5 \mathrm{~h}$ of $10 \mathrm{~Gy}$ radiation exposure, IGFBP-3, EGFR, and phosphorylated DNA-PKcs expression was found to be increased in the nucleus (Figure 4B). Furthermore, these complexes were increased in OSCC cells exposed to 10 Gy radiation (Figure 4C). Next, we examined the expression of IGFBP-3 and DNA-PKcs in post-operative OSCC specimens via immunohistochemistry. Interestingly, IGFBP-3 and DNA-PKcs expression levels were found to be increased in the surviving tumour cells of most cases after preoperative chemoradiotherapy (Figure 4D-F). These findings suggest that IGFBP-3 contributes to cell survival by promoting DNA repair mediated by DNA-PKcs activation in OSCC cells.

\section{Discussion}

Here, we report several meaningful findings. First, tissue but not plasma IGFBP-3 expression was found to be associated with chemoradiotherapy efficacy and prognosis in patients with OSCC. Second, IGFBP-3 levels were significantly increased in CRR OSCC cell lines. Third, IGFBP-3 knockdown increased radiosensitivity. Finally, IGFBP-3 was found to directly interact with EGFR and phosphorylated DNA-PKcs in the nucleus of irradiated OSCC cells and was associated with DNA repair. To our knowledge, there have been no other reports demonstrating the contribution of IGFBP-3 to both therapeutic resistance and poor OSCC prognosis.

Nevertheless, some studies have shown significant associations between tumour IGFBP-3 levels and cancer prognosis [16,17]. However, the clinical importance of tissue IGFBP-3 levels may differ among different tumour types [7]. In oesophageal cancer, IGFBP-3 was reported to inhibit tumour cell growth and induce apoptosis after radiotherapy [26,27]. In lung cancer, cisplatin-resistant cells exhibit reduced IGFBP3 expression [28]. In contrast, our findings indicate that IGFBP-3 can promote proliferation and increase cell survival after irradiation in OSCC. Moreover, IGFBP-3 depletion did not affect OSCC cell sensitivity to chemotherapeutic drugs. Other studies have reported that overexpression of IGFBP-3 is correlated with increased tumour size and lymph node metastasis in patients with OSCC [29,30], suggesting that IGFBP-3 may enhance malignancy in OSCC. Although tumour IGFBP-3 may contribute to tumour progression in OSCC, these discrepancies reflect the diversity of IGFBP-3 functions, including IGF-dependent and independent effects, in different types of cancers.

The association between tumour IGFBP-3 and circulating IGFBP-3, functioning as the main carrier of IGF-I and IGF-II, is yet to be fully elucidated. Moreover, the evidence for an association between circulating IGFBP-3 and either cancer risk or prognosis in different cancer types is inconsistent [8-12,31]. Here, we showed that plasma levels of IGFBP-3 were not associated with tissue levels of IGFBP-3, clinicopathological features, or patient prognosis in OSCC. These results indicate that unlike IGFBP-3 expression in tumour tissue, circulating IGFBP-3 may play a biologically different role.

Nuclear IGFBP-3 has been identified in human keratinocyte cell line [32] and human prostate cancer tissues [33]; indeed, this protein is known to have a functional nuclear localisation signal [34]. EGFR also has a nuclear localisation signal domain and increased nuclear localisation has been reported to enhance therapeutic resistance through associations with DNA-PKcs activation [35]. In a previous study where breast cancer cells were treated with DSB-inducing agents, Lin et al. [36] demonstrated that IGFBP-3 can form complexes with EGFR and DNA-PKcs after treatment with DNA-damaging drugs. It was also shown that upon IGFBP-3 knockdown, DNA-PKcs phosphorylation and EGFR-DNA-PKcs complex formation in the nucleus are inhibited and that NHEJ activity is also decreased. In the present study, we demonstrated that IGFBP-3 is involved in decreased DSB-DNA damage which is mediated by DNA-PKcs activation with the formation of the aforementioned complex and that high tumour IGFBP-3 levels are associated with reduced chemoradiotherapy efficacy and poor prognosis in OSCC. 
Taken together, these results suggest that IGFBP-3 may play a key role in DNA damage-inducing therapy, thus contributing to poor clinical outcomes.

We previously established CRR cells that continue to grow even after daily exposure to an X-ray dose of 2 Gy or more than $60 \mathrm{~Gy}$, and showed that these cells efficiently repair irradiation-induced DSBs [20]. The CRR cell line is very useful for analysing the biological properties of radioresistant cells; thus, we used two CRR OSCC cell lines in this study and observed, for the first time, IGFBP-3 overexpression in these cell lines. Furthermore, it is noteworthy that blockade of IGFBP-3 augmented CRR cell radiosensitivity, suggesting that IGFBP-3 is a promising therapeutic target for overcoming OSCC radioresistance.

There are several limitations to our study. First, the obtained findings were mainly based on in vitro data, except for immunohistochemical analysis of tissues and clinical data from patients with OSCC. Second, although radiation-induced DSBs are repaired by two major pathways, namely NHEJ and HR, our analysis focused on the relationship between IGFBP-3 and the NHEJ protein DNA-PKcs. Finally, other mechanisms are involved in radioresistance, not only DNA repair, including several stress-responsive signalling pathways such as reactive oxygen species generation and activation of cytoprotective autophagy [37]. Therefore, further studies are required to confirm the effects of a combination therapy of IGFBP-3-targeting drugs and radiotherapy on in vivo models and to assess the relationship between IGFBP-3 and the HR DNA repair pathway, as well as other stress-responsive signalling pathways, in radioresistance.

\section{Materials and Methods}

\subsection{Clinical Samples}

For the histopathological analysis, tissue samples were obtained from 52 patients with advanced OSCC treated at Kumamoto University Hospital between October 2003 and June 2011. In addition, blood plasma samples were obtained from 30 of the 52 patients; plasma was separated by centrifugation and stored at $-80^{\circ} \mathrm{C}$ until subsequent analysis. All patients were treated preoperatively with a total dose of $30 \mathrm{~Gy}$ of concurrent chemoradiotherapy, which was followed by curative surgery as a phase II study [38,39]. Radiotherapy was administered daily at 2 Gy five times per week for 15 days. All tumours were staged according to the TNM classification of the AJCC eighth edition (2017); the degree of differentiation was determined according to the grade classification of the WHO. This study was performed in accordance with the guidelines of the Ethics Committee of Kumamoto University (project identification code: SENSHIN No.2389 and RINRI No.1427). Informed consent was obtained from all patients prior to the biopsy and operation based on the guidelines of the Kumamoto University (SENSHIN No.2389). The present study is a retrospective analysis, which does not have individual consent, however guarantees participation in the study and the opportunity to refuse participation in an opt-out format (RINRI No.1427).

\subsection{Immunohistochemical Staining and Evaluation}

Protein levels in OSCC tissue sections were analysed by immunohistochemistry, as previously described [39]. Briefly, tissue sections (4- $\mu \mathrm{m}$ thick) were deparaffinised, rehydrated using a graded alcohol series, and probed with anti-human IGFBP-3 (1:50; MAB305; R\&D, Minneapolis, MN, USA) and anti-human DNA-PKcs (1:200; 3H6; Cell Signaling Technology, Danvers, MA, USA) by incubating samples at $4{ }^{\circ} \mathrm{C}$ overnight in a humid chamber. Then, sequential 60 -min incubations with secondary antibodies (Dako EnVision + System-HRP Labeled Polymer; Agilent Technologies, Santa Clara, CA, USA) and visualisation with the Dako Liquid DAB + Substrate Chromogen System (Agilent Technologies) were performed. All slides were lightly counterstained with haematoxylin for $30 \mathrm{~s}$ prior to dehydration and mounting. Immunoreactivity for IGFBP-3 expression was evaluated by three observers blinded to patient clinical status. For each specimen, one score was assigned according to the proportion of positive cells as follows: $<25 \%, 0$ points; $25-50 \%, 1$ point; $51-75 \%, 2$ points; 
$>75 \%, 3$ points. A second score was assigned according to staining intensity, with negative staining considered 0 points, weak staining 1 point, moderate staining 2 points, and strong staining 3 points. IGFBP-3 expression scores were then calculated by multiplying the two scores. If the expression score was $\geq 4$, the tissue was considered to have high expression.

\subsection{Cell lines and Culture}

We obtained human OSCC cell lines derived from primary tumours, namely SAS and HSC-2, from the Japanese Collection of Research Bioresources Bank of the National Institutes of Biomedical Innovation, Health and Nutrition (Osaka, Japan). In the present study, HSC-2 cells were simply designated HSC2. The CRR cell lines SAS-R and HSC2-R were derived from SAS and HSC2 cells, respectively, by exposing cells to gradually increasing X-ray doses $[18,20]$. These cells continued to proliferate with daily 2-Gy irradiation for more than 30 days in vitro and were resistant to irradiation. Cells were cultured in DMEM supplemented with $10 \%$ FBS in a humidified atmosphere of $5 \% \mathrm{CO}_{2}$ at $37^{\circ} \mathrm{C}$.

\subsection{Irradiation}

Irradiation doses of 2, 6, and 10 Gy were administered with a 150-KVp X-ray generator (MBR-1520R; Hitachi, Tokyo, Japan) with a total filtration of $0.5-\mathrm{mm}$ aluminium plus a 0.1-mm copper filter. The dose rate $\left(1.01 \mathrm{~Gy} \cdot \mathrm{min}^{-1}\right)$ was measured with a thimble ionisation chamber (IC 17A; Far West Technology, Goleta, CA, USA).

\section{5. siRNA Transfection}

Twenty-four hours prior to transfection, SAS and HSC2 cells were diluted in fresh medium without antibiotics. They were then transfected with IGFBP-3-specific siRNA ( $20 \mathrm{nM}$; Stealth siRNA; Invitrogen, Carlsbad, CA, USA) using Lipofectamine RNAi MAX (Invitrogen), as per the manufacturer's instructions. Cells were harvested $48 \mathrm{~h}$ post-transfection.

\subsection{RNA Isolation and $q R T-P C R$}

Total RNA was isolated using the mirVana miRNA Isolation Kit (Life Technologies, Carlsbad, CA, USA) and then reverse-transcribed to cDNA using the ReverTra Ace qPCR RT Kit (Toyobo, Osaka, Japan). qPCR was performed using Thunderbird SYBR qPCR Mix (Toyobo) on a Light Cycler 1.5 (Roche, Basel, Switzerland). We used the comparative Ct (DDCt) method to determine fold-changes in expression levels using glyceraldehyde-3-phosphate dehydrogenase (GAPDH) as a housekeeping gene. Each sample was run in triplicate. The following primers were used: IGFBP-3 forward, 5'-CAAGCGGGAGACAGAA-3' and reverse, 5' -GGACTCAGCACATTGAGGAACTT-3'; and GAPDH forward, $5^{\prime}$-CTGGGCTACACTGAGC-3' and reverse, $5^{\prime}$-AAGTGGTCGTTGAGGG- $3^{\prime}$. Cycling conditions were as follows: initial denaturation at $98^{\circ} \mathrm{C}$ for $5 \mathrm{~min}$, followed by 45 cycles of $98^{\circ} \mathrm{C}$ for $15 \mathrm{~s}, 58^{\circ} \mathrm{C}$ for $30 \mathrm{~s}$, and $72{ }^{\circ} \mathrm{C}$ for $60 \mathrm{~s}$. PCR data were collected from three independent experiments.

\subsection{HDS Assays}

HDS assays were performed as described by Kuwahara et al. [21,40]. Exponentially growing cells $\left(5 \times 10^{5}\right)$ were seeded in 60-mm tissue culture dishes (AGG Inc., Tokyo, Japan) and incubated in DMEM supplemented with $10 \%$ FBS for $48 \mathrm{~h}$. Cells were transfected with scrambled siRNA and then exposed to 2, 6, and $10 \mathrm{~Gy}$. After $72 \mathrm{~h}, 10 \%$ of the cells in each flask were seeded in a new $60-\mathrm{mm}$ culture dish and incubated for $72 \mathrm{~h}$. Total cell numbers in each culture dish were determined using Trypan blue exclusion, and cell survival was plotted. 


\subsection{Clonogenic Assays}

After irradiating siRNA-transfected cells with $6 \mathrm{~Gy}$, the cells $\left(1 \times 10^{3}\right)$ were seeded in a $60-\mathrm{mm}$ culture dish coated with gelatine (AGG Inc.) and cultured in DMEM supplemented with 10\% FBS for 10 days. Next, the cells were fixed with $99.5 \%$ methanol and stained with Giemsa solution (Wako, Osaka, Japan).

\subsection{Immunofluorescent Staining and Evaluation}

Cells $\left(2 \times 10^{4}\right)$ were transfected with siRNA, seeded on glass slides (Merck Millipore, Burlingame, CA, USA), cultured in DMEM supplemented with 10\% FBS for $24 \mathrm{~h}$, and irradiated with $10 \mathrm{~Gy}$. After $0.5 \mathrm{~h}$ (for $\gamma$-H2AX and pDNA-PKcs) or $24 \mathrm{~h}$ (for $\gamma$-H2AX), cells were fixed for $30 \mathrm{~min}$ with $4 \%$ paraformaldehyde in PBS. Then, cells were washed with PBS-T for 5 min and blocked with PBS-T containing 5\% BSA for $5 \mathrm{~min}$ on ice. Next, cells were incubated for $2 \mathrm{~h}$ at room temperature with primary antibodies against phosphorylated histone H2AX $(\gamma-\mathrm{H} 2 \mathrm{AX} ; 1: 400$; cat\# 613401; BioLegend, San Diego, CA, USA), IGFBP-3 (1:50; H-98; Santa Cruz Biotechnology, Dallas, TX, USA), and S2056-phopho-DNA-PKcs (1:200; ab18192; Abcam, Cambridge, UK) in PBS-T with 1\% BSA. Glass slides were then washed with PBS-T three times ( 5 min each), and cells were incubated at room temperature for $1.5 \mathrm{~h}$ with secondary antibodies (Alexa Fluor 488 and 594 donkey anti-rabbit and/or anti-mouse IgG; Life Technologies) in PBS-T with 1\% BSA. After washing with PBS, cells were counterstained and mounted with Vectashield (Vector Laboratories, Inc., Burlingame, CA, USA) and then imaged using a fluorescent microscope (BZ-X700; Keyence, Osaka, Japan). Cells were considered $\gamma$-H2AX-positive if they had $>10$ foci per nucleus [41].

\subsection{Western Blot Analysis}

Whole-cell and nuclear proteins (Minute Cytoplasmic and Nuclear Extraction Kits; Invent Biotechnologies, Inc., Eden Prairie, MN, USA) were separated by 5\% or 12.5\% SDS-PAGE, transferred to nitrocellulose membranes, and probed with antibodies specific for IGFBP-3 (1:200; H-98; Santa Cruz Biotechnology), epidermal growth factor receptor (EGFR) (1:1000; D38B1; Cell Signaling Technology), DNA-PKcs (1:1000; 3H6; Cell Signaling Technology), phospho-DNA-PKcs (S2056) (1:400; ab18192; Abcam), lamin B1 (1:1000; Abcam), and $\beta$-actin (1:5000; Sigma-Aldrich, St Louis, MO, USA). After incubating the membranes overnight at $4{ }^{\circ} \mathrm{C}$, they were washed, incubated with the appropriate horseradish peroxidase-conjugated secondary antibodies, and developed using the ECL prime detection kit (GE Healthcare, Chicago, IL, USA). The emitted light was measured using the C-DiGit blot scanner and the images were analyzed using Image studio for C-Digit (LI-COR Biosciences, Lincoln, NE, USA). Densitometry readings and the whole blot images are provided in the Supplementary Materials.

\subsection{Immunoprecipitation}

Proteins were extracted in RIPA buffer (s25 mM tris- $\mathrm{HCl}$ (pH 7.6), $150 \mathrm{mM} \mathrm{NaCl}, 1 \% \mathrm{NP}-40,1 \%$ sodium deoxycholate, and $0.1 \%$ SDS) with a protease inhibitor cocktail (Roche Diagnostics). Total purified proteins were incubated with $5 \mathrm{mg}$ of antibody specific for IGFBP-3 (Santa Cruz Biotechnology) to form immunocomplexes, which were precipitated with protein A-Sepharose (GE Healthcare). Finally, immunocomplexes were subjected to Western blotting.

\subsection{Cell Proliferation Assays}

Cell proliferation was determined using the cell proliferation reagent WST-8 (Cell Counting Kit-8; Dojindo, Kumamoto, Japan). In brief, for each condition, $3 \times 10^{3}$ cells were seeded in 96-well plates in $100 \mathrm{~mL}$ of medium in quadruplicate. At 24, 48, and $72 \mathrm{~h}$, WST-8 reagent was added at a 1:10 dilution and plates were incubated for an additional $1 \mathrm{~h}$ at $37^{\circ} \mathrm{C}$. The absorbance was measured at 690/480 nm. Data were collected from three independent experiments. 


\subsection{Enzyme-Linked Immunosorbent Assay (ELISA) for Plasma IGFBP-3}

Plasma IGFBP-3 levels were measured using a Human IGFBP-3 Quantikine ELISA Kit (R\&D Systems) according to the manufacturer's instructions.

\subsection{Statistical Analysis}

Differences in mean values between two groups were analysed using Student's $t$-tests, while differences in mean values among multiple groups were analysed by one-way ANOVA with the Bonferroni/Dunn test. For small sample sizes showing normal distribution, Student's $t$-tests were performed. For tissue specimens, the $\chi 2$-test was used to determine associations between IGFBP-3 expression and clinical parameters. A Fisher's exact test was used when one or more cells had expected values $<5$. A survival analysis was performed using the Kaplan-Meier method. The log-rank test was used to determine correlations between IGFBP-3 expression and patient survival. A multivariate survival analysis was performed using the Cox regression model to determine the effects of IGFBP-3 expression on OS and DFS. All $p$-values were based on two-tailed statistical analyses; $p$-values < 0.05 were considered statistically significant. All analyses were performed with JMP 9 software (SAS Institute Inc, Cary, NC, USA).

\section{Conclusions}

Here, we highlighted the potential importance of IGFBP-3 in radioresistant OSCC. Our findings indicate that tumour IGFBP-3 expression can be exploited to predict responses to chemoradiotherapy and that IGFBP-3 may represent a novel prognostic factor. Therapies targeting IGFBP-3-dependent DNA repair combined with radiotherapy also represent a promising new approach for overcoming OSCC radioresistance.

Supplementary Materials: The following are available online at http://www.mdpi.com/2072-6694/12/2/494/s1, Figure S1: Relationship between tumour IGFBP-3 levels and plasma IGFBP-3 levels in patients with oral squamous cell carcinoma (OSCC), Figure S2: Differences in radiosensitivity between clinically relevant radioresistant (CRR) cells and parental cells, Figure S3: IGFBP-3 knockdown inhibits cell proliferation in OSCC cells, Figure S4, IGFBP-3 knockdown does not affect OSCC cell sensitivity to chemotherapeutic drugs, Table S1: Correlation between plasma IGFBP3 levels and clinicopathological factors in 30 patients with oral squamous cell carcinoma (OSCC), Table S2: Prognostic analysis of plasma IGFBP3 levels by the Cox proportional hazards regression model.

Author Contributions: Conceptualisation, J.S. and A.H.; formal analysis, J.S., A.H., R.Y., Y.M., K.K., H.A., H.N. (Hikaru Nakashima), T.Y. and M.N.; investigation, J.S., A.H., R.Y., S.K., S.G., Y.N., K.Y. and Y.K.; data curation, J.S., A.H., R.Y., R.T., R.M. and Y.K.; writing-original draft preparation, J.S.; writing-review and editing, A.H. and H.N.; supervision, Y.K., M.F. and H.N. (Hideki Nakayama); project administration, A.H. and H.N. (Hideki Nakayama); funding acquisition, A.H. and H.N. (Hideki Nakayama). All authors have read and agreed to the published version of the manuscript.

Funding: This work was supported by the Japan Society for the Promotion of Science (JSPS) KAKENHI, grant numbers JP16K20595, JP18K09727, and JP18H03005.

Acknowledgments: We thank Editage (http://www.editage.jp) for English language editing.

Conflicts of Interest: The authors declare no conflict of interest.

\section{References}

1. Siegel, R.L.; Miller, K.D.; Jemal, A. Cancer statistics, 2016. CA Cancer J. Clin. 2016, 66, 7-30. [CrossRef] [PubMed]

2. Gupta, S.; Kong, W.; Peng, Y.; Miao, Q.; Mackillop, W.J. Temporal trends in the incidence and survival of cancers of the upper aerodigestive tract in Ontario and the United States. Int. J. Cancer 2009, 125, 2159-2165. [CrossRef] [PubMed]

3. Zhou, S.; Ye, W.; Shao, Q.; Zhang, M.; Liang, J. Nrf2 is a potential therapeutic target in radioresistance in human cancer. Crit. Rev. Oncol. Hematol. 2013, 88, 706-715. [CrossRef] [PubMed]

4. Yamamoto, V.N.; Thylur, D.S.; Bauschard, M.; Schmale, I.; Sinha, U.K. Overcoming radioresistance in head and neck squamous cell carcinoma. Oral Oncol. 2016, 63, 44-51. [CrossRef] [PubMed] 
5. Daza, D.O.; Sundstrom, G.; Bergqvist, C.A.; Duan, C.; Larhammar, D. Evolution of the insulin-like growth factor binding protein (IGFBP) family. Endocrinology 2011, 152, 2278-2289. [CrossRef]

6. Baxter, R.C. Nuclear actions of insulin-like growth factor binding protein-3. Gene 2015, 569, 7-13. [CrossRef]

7. Baxter, R.C. IGF binding proteins in cancer: Mechanistic and clinical insights. Nat. Rev. Cancer 2014, 14, 329-341. [CrossRef]

8. Rohrmann, S.; Grote, V.A.; Becker, S.; Rinaldi, S.; Tjønneland, A.; Roswall, N.; Grønbæk, H.; Overvad, K.; Boutron-Ruault, M.C.; Clavel-Chapelon, F.; et al. Concentrations of IGF-I and IGFBP-3 and pancreatic cancer risk in the European Prospective Investigation into Cancer and Nutrition. Br. J. Cancer 2012, 106, 1004-1010. [CrossRef]

9. Wolpin, B.M.; Meyerhardt, J.A.; Chan, A.T.; Ng, K.; Chan, J.A.; Wu, K.; Pollak, M.N.; Giovannucci, E.L.; Fuchs, C.S. Insulin, the insulin-like growth factor axis, and mortality in patients with nonmetastatic colorectal cancer. J. Clin. Oncol. 2009, 27, 176-185. [CrossRef]

10. Rinaldi, S.; Cleveland, R.; Norat, T.; Biessy, C.; Rohrmann, S.; Linseisen, J.; Boeing, H.; Pischon, T.; Panico, S.; Agnoli, C.; et al. Serum levels of IGF-I, IGFBP-3 and colorectal cancer risk: Results from the EPIC cohort, plus a meta-analysis of prospective studies. Int. J. Cancer 2010, 126, 1702-1715. [CrossRef]

11. Peeters, P.H.; Lukanova, A.; Allen, N.; Berrino, F.; Key, T.; Dossus, L.; Rinaldi, S.; van Gils, C.H.; Bueno-de-Mesquita, H.B.; Boeing, H.; et al. Serum IGF-I, its major binding protein (IGFBP-3) and epithelial ovarian cancer risk: The European Prospective Investigation into Cancer and Nutrition (EPIC). Endocr. Relat. Cancer 2007, 14, 81-90. [CrossRef] [PubMed]

12. Vatten, L.J.; Holly, J.M.; Gunnell, D.; Tretli, S. Nested case-control study of the association of circulating levels of serum insulin-like growth factor I and insulin-like growth factor binding protein 3 with breast cancer in young women in Norway. Cancer Epidemiol. Biomark. Prev. 2008, 17, 2097-2100. [CrossRef] [PubMed]

13. Chen, B.; Liu, S.; Xu, W.; Wang, X.; Zhao, W.; Wu, J. IGF-I and IGFBP-3 and the risk of lung cancer: A meta-analysis based on nested case-control studies. J. Exp. Clin. Cancer Res. 2009, 28, 89. [CrossRef] [PubMed]

14. Johansson, M.; McKay, J.D.; Rinaldi, S.; Wiklund, F.; Adami, H.O.; Grönberg, H.; Kaaks, R.; Stattin, P. Genetic and plasma variation of insulin-like growth factor binding proteins in relation to prostate cancer incidence and survival. Prostate 2009, 69, 1281-1291. [CrossRef] [PubMed]

15. Roddam, A.W.; Allen, N.E.; Appleby, P.; Key, T.J.; Ferrucci, L.; Carter, H.B.; Metter, E.J.; Chen, C.; Weiss, N.S.; Fitzpatrick, A.; et al. Insulin-like growth factors, their binding proteins, and prostate cancer risk: Analysis of individual patient data from 12 prospective studies. Ann. Int. Med. 2008, 149, 461-471. [PubMed]

16. Sheen-Chen, S.M.; Zhang, H.; Huang, C.C.; Tang, R.P. Insulin-like growth factor-binding protein-3 in breast cancer: Analysis with tissue microarray. Anticancer. Res. 2009, 29, 1131-1135.

17. Santosh, V.; Arivazhagan, A.; Sreekanthreddy, P.; Srinivasan, H.; Thota, B.; Srividya, M.R.; Vrinda, M.; Sridevi, S.; Shailaja, B.C.; Samuel, C.; et al. Grade-specific expression of insulin-like growth factor-binding proteins-2, -3 , and -5 in astrocytomas: IGFBP-3 emerges as a strong predictor of survival in patients with newly diagnosed glioblastoma. Cancer Epidemiol. Biomark. Prev. 2010, 19, 1399-1408. [CrossRef]

18. Kuwahara, Y.; Roudkenar, M.H.; Urushihara, Y.; Saito, Y.; Tomita, K.; Roushandeh, A.M.; Sato, T.; Kurimasa, A.; Fukumoto, M. Clinically relevant radioresistant cell line: A simple model to understand cancer radioresistance. Med. Mol. Morphol. 2017, 50, 195-204. [CrossRef]

19. Jackson, S.P.; Bartek, J. The DNA-damage response in human biology and disease. Nature 2009, 461, 1071-1078. [CrossRef]

20. Kuwahara, Y.; Li, L.; Baba, T.; Nakagawa, H.; Shimura, T.; Yamamoto, Y.; Ohkubo, Y.; Fukumoto, M. Clinically relevant radioresistant cells efficiently repair DNA double-strand breaks induced by X-rays. Cancer Sci. 2009, 100, 747-752. [CrossRef]

21. Matsuoka, Y.; Nakayama, H.; Yoshida, R.; Hirosue, A.; Nagata, M.; Tanaka, T.; Kawahara, K.; Sakata, J.; Arita, H.; Nakashima, H.; et al. IL-6 controls resistance to radiation by suppressing oxidative stress via the Nrf2-antioxidant pathway in oral squamous cell carcinoma. Br. J. Cancer 2016, 115, 1234-1244. [CrossRef] [PubMed]

22. Van Gent, D.C.; Hoeijmakers, J.H.; Kanaar, R. Chromosomal stability and the DNA double-stranded break connection. Nat. Rev. Genet. 2001, 2, 196-206. [CrossRef]

23. Ferguson, D.O.; Alt, F.W. DNA double strand break repair and chromosomal translocation: Lessons from animal models. Oncogene 2001, 20, 5572-5579. [CrossRef] [PubMed]

24. Ryu, J.S.; Um, J.H.; Kang, C.D.; Bae, J.H.; Kim, D.U.; Lee, Y.J.; Kim, D.W.; Chung, B.S.; Kim, S.H. Fractionated irradiation leads to restoration of drug sensitivity in MDR cells that correlates with down-regulation of P-gp and DNA-dependent protein kinase activity. Radiat. Res. 2004, 162, 527-535. [CrossRef] [PubMed] 
25. Wanner, G.; Mayer, C.; Kehlbach, R.; Rodemann, H.P.; Dittmann, K. Activation of protein kinase Cepsilon stimulates DNA-repair via epidermal growth factor receptor nuclear accumulation. Radiother. Oncol. 2008, 86, 383-390. [CrossRef]

26. Luo, L.L.; Zhao, L.; Wang, Y.X.; Tian, X.P.; Xi, M.; Shen, J.X.; He, L.R.; Li, Q.Q.; Liu, S.L.; Zhang, P.; et al. Insulin-like growth factor binding protein-3 is a new predictor of radiosensitivity on esophageal squamous cell carcinoma. Sci. Rep. 2015, 5, 17336. [CrossRef]

27. Yoshino, K.; Motoyama, S.; Koyota, S.; Shibuya, K.; Usami, S.; Maruyama, K.; Saito, H.; Minamiya, Y.; Sugiyama, T.; Ogawa, J.I. IGFBP3 and BAG1 enhance radiation-induced apoptosis in squamous esophageal cancer cells. Biochem. Biophys. Res. Commun. 2011, 404, 1070-1075. [CrossRef]

28. Sun, Y.; Zheng, S.; Torossian, A.; Speirs, C.K.; Schleicher, S.; Giacalone, N.J.; Carbone, D.P.; Zhao, Z.; Lu, B. Role of insulin-like growth factor-1 signaling pathway in cisplatin-resistant lung cancer cells. Int. J. Radiat. Oncol. Biol. Phys. 2012, 82, e563-e572. [CrossRef]

29. Zhong, L.P.; Yang, X.; Zhang, L.; Wei, K.J.; Pan, H.Y.; Zhou, X.J.; Li, J.; Chen, W.T.; Zhang, Z.Y. Overexpression of insulin-like growth factor binding protein 3 in oral squamous cell carcinoma. Oncol. Rep. 2008, 20, 1441-1447. [CrossRef]

30. Yen, Y.C.; Hsiao, J.R.; Jiang, S.S.; Chang, J.S.; Wang, S.H.; Shen, Y.Y.; Chen, C.H.; Chang, I.S.; Chang, J.Y.; Chen, Y.W. Insulin-like growth factor-independent insulin-like growth factor binding protein 3 promotes cell migration and lymph node metastasis of oral squamous cell carcinoma cells by requirement of integrin $\beta 1$. Oncotarget 2015, 6, 41837-41855. [CrossRef]

31. Major, J.M.; Pollak, M.N.; Snyder, K.; Virtamo, J.; Albanes, D. Insulin-like growth factors and risk of kidney cancer in men. Br. J. Cancer 2010, 103, 132-135. [CrossRef] [PubMed]

32. Wraight, C.J.; Liepe, I.J.; White, P.J.; Hibbs, A.R.; Werther, G.A. Intranuclear localization of insulin-like growth factor binding protein-3 (IGFBP-3) during cell division in human keratinocytes. J. Investig. Dermatol. 1998, 111, 239-242. [CrossRef]

33. Seligson, D.B.; Yu, H.; Tze, S.; Said, J.; Pantuck, A.J.; Cohen, P.; Lee, K.W. IGFBP-3 nuclear localization predicts human prostate cancer recurrence. Horm. Cancer 2013, 4, 12-23. [CrossRef] [PubMed]

34. Schedlich, L.J.; Young, T.F.; Firth, S.M.; Baxter, R.C. Insulin-like growth factor-binding protein (IGFBP)-3 and IGFBP-5 share a common nuclear transport pathway in T47D human breast carcinoma cells. J. Biol. Chem. 1998, 273, 18347-18352. [CrossRef] [PubMed]

35. Liccardi, G.; Hartley, J.A.; Hochhauser, D. EGFR nuclear translocation modulates DNA repair following cisplatin and ionizing radiation treatment. Cancer Res. 2011, 71, 1103-1114. [CrossRef] [PubMed]

36. Lin, M.Z.; Marzec, K.A.; Martin, J.L.; Baxter, R.C. The role of insulin-like growth factor binding protein-3 in the breast cancer cell response to DNA-damaging agents. Oncogene 2014, 33, 85-96. [CrossRef]

37. Kim, W.; Lee, S.; Seo, D.; Kim, D.; Kim, K.; Kim, E.; Kang, J.; Seong, K.M.; Youn, H.; Youn, B. Cellular stress responses in radiotherapy. Cells 2019, 8, 1105. [CrossRef]

38. Nagata, M.; Nakayama, H.; Tanaka, T.; Yoshida, R.; Yoshitake, Y.; Fukuma, D.; Kawahara, K.; Nakagawa, Y.; Ota, K.; Hiraki, A.; et al. Overexpression of cIAP2 contributes to 5-FU resistance and a poor prognosis in oral squamous cell carcinoma. Br. J. Cancer 2011, 105, 1322-1330. [CrossRef]

39. Yoshida, R.; Nakayama, H.; Nagata, M.; Hirosue, A.; Tanaka, T.; Kawahara, K.; Nakagawa, Y.; Matsuoka, Y.; Sakata, J.; Arita, H.; et al. Overexpression of nucleostemin contributes to an advanced malignant phenotype and a poor prognosis in oral squamous cell carcinoma. Br. J. Cancer 2014, 111, 2308-2315. [CrossRef]

40. Kuwahara, Y.; Mori, M.; Oikawa, T.; Shimura, T.; Ohtake, Y.; Mori, S.; Ohkubo, Y.; Fukumoto, M. The modified high-density survival assay is the useful tool to predict the effectiveness of fractionated radiation exposure. J. Radiat. Res. 2010, 51, 297-302. [CrossRef]

41. Taneja, N.; Davis, M.; Choy, J.S.; Beckett, M.A.; Singh, R.; Kron, S.J.; Weichselbaum, R.R. Histone H2AX phosphorylation as a predictor of radiosensitivity and target for radiotherapy. J. Biol. Chem. 2004, 279, 2273-2280. [CrossRef] [PubMed]

(C) 2020 by the authors. Licensee MDPI, Basel, Switzerland. This article is an open access article distributed under the terms and conditions of the Creative Commons Attribution (CC BY) license (http://creativecommons.org/licenses/by/4.0/). 